\section{Investigation of Adjuncts Use in J. F. Kennedy's Speech for the Members of Congress and Diplomatic Corps of Latin America on 13 March 1961}

\author{
1 Mercya Christ Sita Dewi
}

1 Universitas Tidar, Indonesia

\begin{abstract}
This descriptive qualitative study investigates the types of adjuncts use in a spoken language grammar of J. F. Kennedy's speech on 13 March 1961. Further, the study does examine the occurrence of each adjunct used in the recording. As it is described, adjuncts are an optional or structurally dispensable part of a sentence, clause, or phrase, when omitted, will not affect the remainder of the sentence being an element of clause structure with an adverbial function. In this current study, the researcher listed fourteen groups of adjuncts in the recording. The theory used to examine this study is stated in Carter \& McCarthy's (2006). The result conveys that the total numbers of adjuncts used in the speech are 75 adjuncts. In which adjuncts of place become the most frequent adjuncts in the speech. Next, focusing adjuncts be the most frequent number two with 14 total occurrences. The data show modal adjuncts could not be identified in the recording.
\end{abstract}

\section{Keywords}

adjunct

discourse

adverbial type
Ethical Lingua

Vol. 7, No. 2, 2020

ISSN 2355-3448 (Print)

ISSN 2540-9190 (Online)

Corresponding Email

Mercya Christ Sita Dewi

mercyachrist@gmail.com

Article's History

Submitted 20 June 2020

Revised 16 September 2020

Accepted 16 September 2020

DOI

10.30605/25409190.187

Copyright $\odot 2020$

The Author(s)

This article is licensed under CC BY-NC-SA 4.0 License

\section{(cc) EY-NC-SA}




\section{Investigation of Adjuncts Use in J. F. Kennedy's Speech for the Members of Congress and Diplomatic Corps of Latin America on 13 March}

1961

The study of syntax represents the analysis of the principles, rules, and processes which determine the structure of sentences in human languages. Several linguists and scholars have revealed the research on this field. Syntax as a complex unit represents a branch of linguistics study that concentrates on sentence patterns or how different parts of sentences are structured together by a set of rules. Syntax also can be seen as the governing principles defining which combinations of linguistic symbols are deemed to be correctly structured by natural language speakers. Chomsky (2002) explains, "Syntax is the study of the principles and processes by which sentences are constructed in particular languages." In linguistics, a sentence can be comprised of five units based on their elements as follows: subject, verb, complement, object, and adverbial (Putra \& Sulatra, 2016)

Adjuncts as a sub-classification of an adverbial are an optional or structurally dispensable part of a sentence, clause, or phrase, when omitted, will not affect the remainder of the sentence being an element of clause structure with adverbial function (Dhena, 2016). The level of adjuncts is purposed to express the place, process, time, cause, and reason. Borjars \& Burridge (2010) articulate, "Adjunct are typical adverbial, they are optional and they provide circumstantial to do with location, manner, attitude, time, instrument, degree, frequency and so on." The previous researchers deliver different perspectives on the classification of adjuncts. Hasselgard (2010) synthesizes previous theories about sub-classification of adjuncts from Quirk et al., (1985), Bieber et al., (1999), and Halliday (1985). She distributes the semantic classification of adjuncts used in the most of present study into eleven classes, as follows: space, time, manner, contingency, respect, degree, participant, situation, comparison, focus, and viewpoint.

In another book of Carter \& McCarthy (2006) classify adjuncts into fourteen discrete types of meaning that adjuncts mostly express as follow: manner, place, time, duration, definite and indefinite frequency, reason, purpose, degree, intensity, focusing, modal, evaluate, viewpoint, also linking. Quirk et al., (1985) as cited in Ojetunde \& Okanlawon (2012) distribute adjuncts into eight classes. These are; viewpoint, focusing, intensifier, process, subjects, place, time, and others, which can be described contingency adjuncts. As adjuncts control further information in which can be removed, the form of adjuncts can be a phrase, only a word, even clause.

Predominantly, the study of adjuncts widely focuses on the issue from various angels of adjuncts, based on the sub-classification given. As an example, Dhena (2016) examined manner adjuncts in a novel according to the position and form approach. She revealed out that the positions of manner adjunct could occur in the initial position, medial position, and final position. In a similar vein, Putra \& Sulatra (2016) concentrated on time adjuncts in written English, specifically in a Harry Potter novel. He found out there were four types of time adjuncts, which are time, duration, frequency, and other relationships in which adjuncts time adjuncts be the most dominant adjuncts. He also examined the structure of adjuncts that 
found. In the research, adjuncts could be realized as a prepositional phrase, adverb phrase, the noun phrase, and prepositional phrase and others. On the other hand, Ojetunde \& Okanlawon (2012) carried out a study of the most typical adjuncts used by selected students in written text and conversational discourse. The finding revealed out three types of adjuncts were frequently used by students both in spoken discourse and in written text as follows: time, place, and process. A number of studies have been carried out examining the use of adjuncts mostly to add information concerning time, place, and manner adjuncts.

Those reviews of published academic research studies above accentuate that adjuncts play crucial roles in grammar structure, both written and spoken grammar as it assists to highlight or determine particular information. However, the current study purposes to investigate the types and frequency of each adjunct use in spoken English grammar or spoken discourse by analyzing J. F. Kennedy's speech on March 13, 1961. Following the theory offered by Carter \& McCarthy (2006) as the reference of the sub-classification of adjuncts. In accordance with the theory, fourteen types of adjuncts will be examined in this current study. All these will be explored in detail in the subsequent part of finding and discussion.

\section{Method}

The study collected the data from an audio recording of J. F. Kennedy's speech for the members of congress and diplomatic corps of Latin America on 13 March 1961. The 20 minutes and 58 seconds of audio recording can be accessed on www.jfklibrary.org.

To collect the data, the researcher listened to the audio then accessed the transcript of the speech. In displaying the findings, the researcher identified the data by classifying adjuncts into fourteen subtypes as stated by Carter \& McCarthy (2006). The finding of the research was inserted in a table and supported by a detailed descriptive explanation. The data also displayed the occurrences of each type of adjunct. In analyzing the data, the researcher used a theoretically grounded approach to defining and classifying various kinds of adjuncts. In accordance with the fact, a descriptive qualitative method was applied to investigate the study. Qualitative research provides a connection between data collection, analysis, and interpretation (Gay, Mills \& Airasian, 2011). Fraenkel \& Wallen (1993) described that descriptive qualitative research explains descriptive data from the fact, actual words, or actions of people, involving deep comprehension and description of documents or phenomena. The last step of the study was drawing out a conclusion about the types of adjuncts use in J.F Kennedy's speech and a brief explanation of the type of adjuncts.

\section{Results \& Discussion}

The findings of this study record there are fourteen types of adjuncts found in J.F. Kennedy's speech for the members of congress and diplomatic corps of Latin America on 13 March 1961. Adjuncts of place become the most dominant adjuncts in the speech, it occurs 15 times. Next, adjuncts of focus become the most frequent number two with 14 total occurrences. The data show modal adjuncts could not be identified. The table below provided data of adjuncts in the recording.

The following table conveys the total number of adjuncts occurrence in the recording. The researcher revealed out 75 adjuncts can be identified as displayed in Table 1. 
Table 1. The occurrence of adjuncts

\begin{tabular}{llll}
\hline Adjuncts & Occurrence & Adjuncts & Occurrence \\
\hline Purpose and reason & 6 & Duration & 4 \\
Place & 15 & Manner & 5 \\
Focusing & 14 & Degree and intensity & 5 \\
Time & 9 & Modal & 0 \\
Definite and indefinite frequency & 5 & Evaluative & 1 \\
Linking & 9 & Viewpoint & 2 \\
\hline Total number & & & $\mathbf{7 5}$ \\
\hline
\end{tabular}

\section{Adjuncts of Purpose and Reason}

Table 2. The Frequency of Purpose and Reason Adjuncts

\begin{tabular}{lll}
\hline Purpose and Reason Adjuncts & Time & Occurrence \\
\hline as a citizen ... & $04: 24-04: 26$ & 1 \\
let me be the first... & $04: 27-04: 29$ & 1 \\
a plan to transform... & $06: 57-07: 00$ & 1 \\
let me stress... & $08: 03$ & 1 \\
for its own development... & $09: 44$ & 1 \\
to help each country... & $10: 28$ & 1 \\
\hline Total number & & $\mathbf{6}$ \\
\hline
\end{tabular}

Purpose and reason adjuncts indicate why and for what something happens. Bayu Pratama et al., (2018) state when adjuncts convey purpose, they tend to explain the general issue 'why' or 'what did he/she do something for?' In addition, it explicitly concerns the motivation of certain action is taken. Therefore, to recognize whether or not adjunct brings reason or purpose, the researcher has to recognize the signal word given such as for, to, and if. In the current research, the author found six purpose and reason adjuncts by considering and recognizing the signal word given in the discourse and omitting part of the adjuncts, if the word, phrase or clause does not change the meaning of the rest of the sentence, it can be considered as an adjunct. Mostly, the type of purpose and reason adjuncts are clauses, as it can be noticed in the table above in which in order to introduce the purpose and reason adjuncts.

\section{Adjuncts of Place}

The core of place adjunct is to emphasize the particular place, location, or direction which is stated or delivered in the text or discourse. Hinkel (2002) explains that the adjuncts of place describe the locational frame delivered in the discourse or written text. The results above revealed that the total number of place adjuncts is 15 times. The researcher found out that the most common form of place adjuncts are prepositional phrases. One of the characteristics of adjuncts is mostly realized by a prepositional phrase rather than by a 
nominal group (Halliday, 1985). As an example of the data above, in order to recognize a particular place, J. F. Kennedy would use a preposition at the beginning.

Table 3. The Frequency of Place Adjuncts

\begin{tabular}{|c|c|c|c|c|c|}
\hline Place Adjuncts & Time & Occurrence & Place Adjuncts & Time & Occurrence \\
\hline $\begin{array}{l}\text { to the White } \\
\text { House }\end{array}$ & $00: 31$ & 1 & of the hemisphere & $\begin{array}{l}\text { 06:17; 10:26; } \\
\text { 13:05 }\end{array}$ & 3 \\
\hline $\begin{array}{l}\text { throughout this } \\
\text { hemisphere }\end{array}$ & $00: 32$ & 1 & in this hemisphere & $10: 37 ; 19: 39$ & 2 \\
\hline in the world & 01:04 & 1 & in the United State & $16: 04$ & 1 \\
\hline Here & 02:12 & 1 & in the fields & $19: 19$ & 1 \\
\hline $\begin{array}{l}\text { to the other } \\
\text { lands }\end{array}$ & 03:26 & 1 & in the cities & 19:21 & 1 \\
\hline $\begin{array}{l}\text { to the entire } \\
\text { world }\end{array}$ & 03:49 & 1 & in the schools & $19: 25$ & 1 \\
\hline Total number & & & & & 15 \\
\hline
\end{tabular}

\section{Adjuncts of Focusing}

Focusing adjunct tends to specify a particular event or content of the utterance in a certain way (Carter \& McCarthy, 2006). This adjunct aims to bring a limitation towards the topic, which is being discussed or communicated. It also provides a perspective and assigns responsibility to somebody in a particular situation. In order to analyze this type of adjunct, the researcher has to examine the function and determine whether the word or phrase focusing on and embracing limitation to a certain event or not. The finding revealed out fourteen focusing adjuncts in the J.F. Kennedy's speech. The word 'also' in the recording became the most frequent focusing adjuncts found with contains a meaning that is a piece of additional information.

Table 4. The Frequency of Focusing Adjuncts

\begin{tabular}{lll}
\hline Focusing Adjuncts & Time & Occurrence \\
\hline for the first time & $01: 35$ & 1 \\
also & $03: 28 ; 04: 37 ; 13: 46 ; 14: 32$ & 4 \\
just & $04: 36 ; 08: 59 ; 08: 23$ & 3 \\
only & $08: 05 ; 09: 09 ; 15: 48$ & 3 \\
alone & $08: 13 ; 19: 06$ & 2 \\
soon & $17: 27$ & 1 \\
\hline Total number & & 14 \\
\hline
\end{tabular}


Table 5. The Frequency of Time Adjuncts

\begin{tabular}{lll}
\hline Time Adjuncts & Time & Occurrence \\
\hline today & $00: 32 ; 02: 13$ & 2 \\
this week & $00: 36$ & 1 \\
it was then & $00: 52$ & 1 \\
yet & $03: 39 ; 03: 43 ; 04: 13$ & 3 \\
this evening & $10: 40$ & 1 \\
now & $15: 31$ & 1 \\
\hline Total number & & $\mathbf{9}$ \\
\hline
\end{tabular}

Time adjuncts determine temporal, subsequent proceeding, consecutive, and other relationships between activities and moments that happen in a particular situation in the written text or discourse (Ojetunde \& Okanlawon, 2012). Another function of time adjuncts can be seen to establish tenses use in a particular moment. In the recording, the use of time adjuncts was expressed in prepositional phrases, one-word adverbials, and noun clauses. Quirk et al. (1985) define that time adjuncts can be in the form of clauses or prepositional phrases even noun phrases.

\section{Adjuncts of Frequency}

Frequency adjuncts are used to emphasize and respond to how often a particular event or action mostly occurs. Adjuncts of frequency can be grouped into two major subclasses as follows: (a) definite frequency (in which the frequency can be measured explicitly). It comprises of span frequency and quantity frequency. (b) Indefinite frequency (in which the frequency can be measured implicitly. It contains a usual occurrence, continual frequency, low, and high or zero frequency.

Table 6. The Occurrence of Frequency Adjuncts

\begin{tabular}{llll}
\hline Frequency Adjuncts & Type & Time & Occurrence \\
\hline always & Indefinite & $01: 48 ; 04: 31 ; 18: 25$ & 3 \\
daily & Definite & $05: 12$ & 1 \\
each day & Definite & $05: 27$ & 1 \\
\hline Total number & & & $\mathbf{5}$ \\
\hline
\end{tabular}

\section{Linking Adjuncts}

Nine linking adjuncts are listed on the recording. Ibrahim (2008) delivers a statement that linking adjunct adverbials are used to relate independent grammatical units namely a clause, sentence, and paragraph, or the discourse to become a completely coherent construction. Primarily, the function of linking adjunct is to create successfully, dynamically, and satisfactorily sense of the spoken or written text. As it aims to emphasize the correlation between two or more units of discourse. 
Table 7. The Frequency of Linking Adjuncts

\begin{tabular}{lll}
\hline Linking & Time & Occurrence \\
\hline once again & $02: 04 ; 19: 46 ; 20: 08$ & 3 \\
therefore & $06: 15 ; 17: 18$ & 2 \\
then & $07: 25 ; 08: 48$ & 2 \\
thus & $08: 41$ & 1 \\
in this way & $16: 25$ & 1 \\
\hline Total number & & $\mathbf{9}$ \\
\hline
\end{tabular}

\section{Adjuncts of Duration}

Duration Adjuncts describe how long an event lasts or continuous (Carter \& McCarthy, 2006). Duration adjuncts differ from time adjuncts in terms of time position and relationship. However, adjuncts of duration indicate a stretch of time that can be divided into two main groups namely denoting the length of time and stating the beginning of or the end of an event. According to the findings, most of the duration adjuncts are typical of the length of time in the form of preposition and noun phrases.

Table 8. The Frequency of Duration Adjuncts

\begin{tabular}{lll}
\hline Duration Adjuncts & Time & Occurrence \\
\hline in the long history & $01: 14$ & 1 \\
throughout its history & $02: 00$ & 1 \\
historic decade of & $07: 01-03$ & 1 \\
for a decade & $09: 16$ & 1 \\
\hline Total number & & $\mathbf{4}$ \\
\hline
\end{tabular}

\section{Adjuncts of Manner}

Table 9. The Frequency of Manner Adjuncts

\begin{tabular}{lll}
\hline Manner Adjuncts & Time & Occurrence \\
\hline Immediately & $12: 32$ & 1 \\
Rapidly & $14: 18 ; 14: 22$ & 2 \\
Freely & $17: 44$ & 1 \\
not with an imperialism & $20: 15-18$ & 1 \\
\hline Total number & & $\mathbf{5}$ \\
\hline
\end{tabular}

Five manner adjuncts can be noticed in the J.F. Kennedy's speech on 13 March 1961. The prototypical of manner adjuncts display manner/quality in which explains how something is done or carried out (Hasselgård, 2010). In consonance with the findings, the common way of 
constructing the manner adjuncts are by attaching a -ly suffix to an adjective and change the part of speech into an adverb.

\section{Adjuncts of Degree and Intensity}

Table 10. The Frequency of Degree and Intensity Adjuncts

\begin{tabular}{lll}
\hline Degree and Intensity Adjuncts & Time & Occurrence \\
\hline equally & $06: 07$ & 1 \\
shortly & $09: 19$ & 1 \\
greatly & $10: 12$ & 1 \\
seriously & $12: 16$ & 1 \\
heavily & $12: 59$ & 1 \\
\hline Total number & & $\mathbf{5}$ \\
\hline
\end{tabular}

Five degree and intensity adjuncts were founded in the recording, which aims to emphasize the extent of an event. It sometimes hard to distinguish degree and intensity adjuncts from manner adjunct as mostly degree and intensity adjuncts found were ended by -ly suffix (Hasselgård, 2010). In this instance, to determine the degree and intensity adjunct, Halliday \& Matthiessen (2004) introduces the main function of this adjunct scilicet to emphasize to what extent and to which something is carried out or holds, it expresses intensity, quantity, magnitude, and amount.

\section{Evaluative Adjuncts}

The evaluative adjuncts have an essential goal to give a comment, judgment, and give an opinion of the speaker or writer toward certain action (Carter \& McCarthy, 2006). The study found an evaluative adjunct, which only occurred once in the recording. An example is found in the use of word fully in the following extracts:

"...just as it is also true that many in your own countries have not fully understood..." (04:41).

In the extract given, the word 'fully' conveys a subjective evaluation of the main topic of the recording.

\section{Viewpoint Adjuncts}

Viewpoint adjuncts describe the domain perspective of the speaker's view towards an event or subject of the discussion (Carter \& McCarthy, 2006). For some reason, overlapping occurs between viewpoint and evaluative adjuncts. Nonetheless, the distinctiveness of the evaluative and viewpoint adjuncts is on the perspective given, in which evaluative adjuncts focuses on the personal perspective. While viewpoint adjuncts only concern the topic of the speaker wishes to emphasize. The example of viewpoint adjuncts is found twice in the recording as in the following extracts:

\footnotetext{
"...In the word of Thomas Paine, 'a spark never to be extinguished'..." (03:04)

"...In the word of Jose Figures, 'once dormant people are struggling upward toward the sun, toward a better life'..." (05:51)
} 
Those data above indicated that the speaker delivered his opinion according to someone's perspective.

\section{Modal Adjuncts}

These adjuncts deliver speakers' views or judgments in terms of the probability of events happening in some way (Carter \& McCarthy, 2006). It indicates the way things appear to the speaker and the speaker's attitude to the content of the message. However, the example of modal adjuncts could not be found in the recording as modal adjuncts mostly used to emphasize interpersonal view toward a certain topic (Halliday \& Matthiessen, 2014). In this current case, J.F. Kennedy's speech is typical of formal situation speech in which the language use should be more orderly and precise.

\section{Conclusion}

The study investigates the type of adjuncts and the occurrences of each adjunct recorded in the J. F. Kennedy's speech on 13 March 1961. Adjuncts as a part of adverbial have a particular function to emphasize or deliver further information, in which it will not change the meaning of the discourse when that part is omitted. To examine the types of adjuncts, the researcher has to recognize the characteristics of each adjunct that can be found in the references of the previous study related to the use of adjuncts. Following the discussions above, there are thirteen of the fourteen types of adjuncts can be recognized with the total number of occurrences is 75 . In this current case, adjuncts of place are dominated most of the discourse. While modal adjuncts could not be detected, because of the current data examined use formal language to deliver the message.

However, this study is limited to the types and occurrences of adjuncts only, on the other hand, the field of research on adjuncts is wide and complex. The researcher suggests to the further researchers to develop the area of study on English adjuncts such as the formation, functions, and position of adjuncts in the spoken text.

\section{Acknowledgment}

N/A.

\section{References}

Bayu Pratama, I. G. P., Susini, N. M., \& Gede Suarjaya, A. A. (2018). Forms and Meanings of Adjuncts in James' Fifty Shades of Freed. KULTURISTIK: Jurnal Bahasa Dan Budaya, 2(2), 162-174. https://doi.org/10.22225/kulturistik.2.2.753

Bieber, D., Johansson, S., Leech, G., Conrad, S. \& Finegan, E. (1999). Longman Grammar of Spoken and Written English. Longman.

Borjars, K. \& Burridge, K. (2010). Introducing English Grammar (2nd Ed). Hodder Education.

Carter, R. P., \& McCarthy, M. (2006). Cambridge grammar of English: A comprehensive guide. Cambridge University Press.

Chomsky, N. (2002). On Nature and Language (A. Belletti \& L. Rizzi (eds.)). Cambridge University Press. https://doi.org/10.1017/CB09780511613876

Dhena, Y. (2016). Analysis of Manner Adjuncts Found in the Novel The Little Drummer Girl by John Le Carre. Fakultas Sastra Dan Budaya Unud, 14, 88-95. 
Fraenkel, J. R., \& Wallen, N. E. (1993). How to design and evaluate research in education. 2nd Edition. McGraw-Hill Inc.

Gay, L. R., Mills, G., \& Airasian, P. W. (2011). Educational Research. PEARSON.

Halliday, M. A. K. \& Matthiessen, C. M. I. M. (2004). An Introduction to Functional Grammar. Arnold.

Halliday, M. A. K. \& Matthiessen, C. M. I. M. (2014). An Introduction to Functional Grammar. Routledge.

Halliday, M. A. K. (1985). An Introduction to Functional Grammar. Elward Arnold Publishers Ltd.

Hasselgård, H. (2010). Adjunct Adverbials in English. Cambridge University Press.

Ibrahim, W. J. (2008). The Characteristics of English linking adverbial. Journal of the College of Languages, 18, 8-23. http://search.emarefa.net/detail/BIM-335755

Ojetunde, C. F., \& Okanlawon, B. (2012). An Investigation of Adjuncts in the English of Students in Selected Tertiary Institutions in Nigeria. European Scientific Journal, ESJ, 8(25). http://www.eujournal.org/index.php/esj/article/view/544

Putra, I G. B. W. N., \& Sulatra, I. K. (2016). An Analysis of Time Adjuncts in Harry Potter and Prisoner of Azkaban. Prosiding Prasasti. https://jurnal.uns.ac.id/prosidingprasasti/article/view/1546

Quirk, R., Greenbaum, S., Leech, G., Svartvik, J. A. (1985). Comprehensive Grammar of the English Language. Longman. 